\title{
PENERAPAN NETWORK ATTACHED STORAGE (NAS) BERBASIS RASPBERRY Pi DI LP3SDM AZRA PALEMBANG
}

\author{
R.M. Nasrul Halim ${ }^{1}$ \\ ${ }^{1}$ Fakultas Ilmu Komputer Universitas Bina Darma Palembang \\ Email: ${ }^{1}$ nasrul.zone@gmail.com
}

(Naskah masuk: 12 Desember 2018 untuk diterbitkan: 13 Februari 2019)

\begin{abstract}
Abstrak
Kebutuhan penyimpanan data yang semakin besar seiring dengan berkembangnya teknologi informasi, dibutuhkanlah suatu sistem penyimpanan data yang dapat melayani kebutuhan data secara cepat serta dapat diakses melalui jaringan lokal, salah satunya menggunakan Network Attached Storage (NAS). NAS merupakan sistem penyimpanan yang terhubung dijaringan komputer sehingga proses penyimpanan dan pengambilan data dapat dilakukan di server bagi pengguna yang terhubung ke jaringan. Sistem NAS fleksibel dan dapat disesuaikan jika memerlukan penyimpanan tambahan. Proses penyimpanan data di LP3SDM AZRA Palembang selama ini masih menggunakan media flashdisk dan e-mail untuk pertukaran data sedangkan penyimpanan data dilakukan di laptop masing-masing pegawai dan disimpan di flashdisk. Dalam penelitian ini Raspberry pi digunakan sebagai Server NAS sebagai pengganti PC ataupun server dedicated, dikarenakan harga Raspberry yang cukup murah dibanding PC dan Raspberry tidak membutuhkan spesifikasi perangkat keras yang tinggi serta tidak membutuhkan lisensi perangkat lunak. Hasil dari penelitian ini berupa sistem penyimpanan data menggunakan Raspberry Pi sebagai file server pengganti PC, yang dapat melayani proses penyimpanan dan pertukaran data di LP3SDM AZRA Palembang sehingga dapat memudahkan pekerjaan karyawannya.
\end{abstract}

Kata kunci: NAS, raspberry, LP3SDM AZRA

\section{IMPLEMENTATION OF NETWORK ATTACHED STORAGE (NAS) BASED ON RASPBERRY Pi IN LP3SDM AZRA PALEMBANG}

\begin{abstract}
The need for data storage is increasing along with the development of information technology, it is necessary to a data storage system is needed that can serve data needs quickly that can serve the needs of data quickly and can be accessed through the local network, which one of them using Network Attached Storage (NAS). NAS is a storage system that is connected to a computer network so that the process of storing and retrieving data can be done on the server for users who are connected to the network. The NAS system is flexible and customizable if it requires additional storage. The process of data storage in LP3SDM AZRA Palembang so far still uses flash disk and e-mail for data exchange while data storage is done in each employee laptop and uses flash disk. In this research Raspberry pi is used as a NAS Server instead of a PC or dedicated server, because the price of raspberry is quite cheap compared to $P C$ and Raspberry does not require high hardware specifications and does not require software licenses. The result of this research is data storage system using Raspberry Pi as a PC replacement file server, that can serve the storage and data exchange process in LP3SDM AZRA Palembang so it can facilitates the work of its employees.
\end{abstract}

Keywords: NAS, raspberry, LP3SDM AZRA

\section{PENDAHULUAN}

Berkembangnya teknologi informasi dan komputer saat ini berpengaruh terhadap ukuran kapasitas data yang semakin besar, diikuti dengan jumlah pengguna data juga terus meningkat, hal tersebut berdampak pada kebutuhan media penyimpanan data yang besar pula, terutama pada perusahaan, institusi ataupun lembaga pemerintah dan swasta yang memiliki data-data yang besar yang membutuhkan media penyimpanan data yang fleksibel dan dapat disesuaikan dengan kebutuhan, serta media penyimpanan data yang murah dan mempunyai kinerja yang baik pula, karena mahalnya biaya dan spesifikasi hardware serta lisensi software yang dibutuhkan. Untuk itu dibutuhkanlah suatu media penyimpanan data (file server) yang bervariasi dan murah serta dapat melayani 
kebutuhan data secara cepat serta dapat diakses melalui jaringan lokal, salah satunya menggunakan sistem NAS (Network Attached Storage).

NAS merupakan sebuah server yang menggunakan sistem operasi khusus yang digunakan untuk melayani kebutuhan akan data. NAS dapat berupa hardware yang siap digunakan atau dapat juga berupa sebuah perangkat lunak yang di-installkan dikomputer sehingga dapat berfungsi sebagai NAS server. NAS dapat diakses melalui LAN menggunakan protokol TCP/IP. File transfer protocol (FTP) yang didukung oleh NAS antara lain Network File System, Common Internet File System, File Transfer Protocol dan lain-lain (Defni \& Probowo, 2013). NAS merupakan konsep penyimpanan data bersama-sama di LAN. Agar dapat berkomunikasi di LAN, NAS menggunakan protokol Network File System (NFS) untuk UNIX, Common Internet File System (CIFS) untuk Microsoft Windows, FTP, HTTP dan protokol jaringan lainnya (Dharmendra, 2015).

NAS adalah salah satu solusi dari permasalahan mahalnya penyimpanan yang ada, karena tidak membutuhkan resource hardware yang tinggi untuk berbagi data. NAS merupakan sebuah server yang menggunakan sistem operasi khusus yang digunakan untuk melayani kebutuhan data. NAS dapat diakses melalui LAN menggunakan protokol TCP/IP. NAS tersedia sebagai perangkat komputer yang dibuat khusus untuk difungsikan sebagai file server. Kelebihan appliance jika dibandingkan dengan file server ialah lebih cepat dalam mengakses data, lebih mudah dalam pengelolaan dan konfigurasi. NAS bertanggung jawab dan berfungsi untuk melayani pengelolaan file dari server lain dalam jaringan komputer dan menyediakan akses menggunakan protokol NFS, SMB/CIFS atau AF (Jannah, 2015). Saat ini produk NAS server dedicated sudah banyak dijual secara umum namun dengan harga yang cukup mahal, sehingga dibutuhkanlah suatu produk NAS yang murah. Untuk membangun sistem NAS atau file server yang mudah dan murah dibutuhkan suatu perangkat yang dapat dijadikan sebagai file server.

Beberapa alternatif perangkat pengganti PC atau produk server NAS yang dapat digunakan untuk membangun file server seperti Raspberry pi, Intel Galileo, Arduino. Pada penelitian ini penulis menggunakan perangkat Raspberry $\mathrm{Pi}$, karena Raspberry Pi memiliki spesifikasi perangkat keras yang jauh lebih baik dari pada beberapa perangkat yang lain seperti memliki RAM 1GB serta Raspberry Pi juga dapat melakukan segala hal seperti layaknya sebuah PC. Kekurangan Raspberry $\mathrm{Pi}$ adalah sulit bagi pengguna yang belum memahami sistem operasi Linux.

Raspberry Pi adalah komputer yang berukuran sebesar credit card, yang awalnya dirancang untuk mempromosikan pengajaran tentang ilmu komputer. Raspberry $\mathrm{Pi}$ dibangun menggunakan processor
ARM11. Raspberry Pi menggunakan SD card untuk proses booting sistem operasi. Menggunakan sistem operasi Linux dan didukung dengan bahasa pemrograman python atau PHP. Perangkat ini menggunakan sistem Broadcom BCM2835 pada chip (System-on-a-chip/SoC), terdiri dari processor ARM1176JZF-S 700 MHz, Video grafik IV GPU, dengan 256 MB RAM pada awalnya, selanjutnya meningkat menjadi 512 MB (Yuwono, 2015).

Raspberry Pi 3 seperti merupakan salah satu produk Raspberry Pi yang diluncurkan pada bulan Februari 2016. Memiliki SoC Broadcom BCM2837, dengan processor Mid-core $64 \mathrm{MHz}$ quad-core ARM Cortex-A53, dengan RAM 1GB, menggunakan WLAN 802.11n, dan konektivitas Bluetooth 4.1. Raspberry Pi bersifat open source (berbasis Linux) dan Raspberry Pi bisa dimodifikasi sesuai kebutuhan penggunanya.

Awalnya penggunaan Raspberry $\mathrm{Pi}$ hanya untuk menjalankan program-program perkantoran, namun seiring perkembangan zaman Raspberry Pi dapat juga dimanfaatkan sebagai server ataupun perangkat lainnya. Dalam penelitian ini Raspberry pi digunakan sebagai Server NAS untuk menggantikan PC ataupun server dedicated, dikarenakan harga raspberry yang cukup murah dibanding PC dan Raspberry tidak membutuhkan spesifikasi perangkat keras yang tinggi serta tidak membutuhkan lisensi perangkat lunak. Salah satu lembaga yang membutuhkan media penyimpanan data yang cukup besar di Kota Palembang adalah Lembaga Pendidikan Penelitian dan Pengembangan Sumber Daya Manusia (LP3SDM) AZRA Palembang. Raspberry Pi cocok digunakan di LP3SDM AZRA karena memiliki spesifikasi perangkat keras yang cukup tinggi, dapat diintegrasikan dengan media penyimpanan yang sangat besar serta dapat akses oleh banyak pengguna atau pegawai

LP3SDM AZRA adalah sebuah lembaga yang bertujuan untuk meningkatkan kualitas sumber daya manusia pada umumnya, melalui pendidikan dan latihan (Diklat) dibidang Penelitian dan Evaluasi pada khususnya, untuk menghasilkan karya ilmiah dalam rangka meningkatkan kualitas pendidikan di Indonesia dan di Sumatera Selatan khususnya. Selain diklat, lembaga ini juga memfasilitasi guru dalam seminar karya tulis ilmiah (Halim, 2016). Lembaga ini sudah berdiri selama kurang lebih 8 tahun, dan telah memiliki ribuan peserta yang tersebar di seluruh kabupaten dan kota di Provinsi Sumatera Selatan. Namun dalam proses penyimpanan data-data masih tersebar dan disimpan di masing-masing laptop karyawan karena lembaga ini tidak menyediakan komputer untuk masingmasing karyawan sehingga lembaga ini belum memiliki media penyimpanan data khusus sebagai media penyimpanan data. Data yang disimpan di lembaga ini antara lain data peserta diklat, data penelitian dan lain-lain dalam bentuk berkas dokumen. 
Saat ini LP3SDM AZRA belum memiliki manajemen data yang dikelola dengan baik. Proses peyimpanan dan pertukaran data di LP3SDM AZRA saat ini masih menggunakan media flashdisk dan $e$ mail. Setiap karyawan difasilitasi sebuah flashdisk berukuran 8GB yang dapat menampung seluruh perkerjaan masing-masing karyawan jika sudah selesai dan disimpan di kantor. Jika karyawan ingin meminta data maka harus menggunakan flashdisk atau e-mail kepada karyawan yang memiliki data yang diinginkan. Hal tersebut tentu saja memperlambat kerja karyawan apa lagi jika karyawan yang tersebut sedang tidak berada di kantor dan tidak memiliki akses internet untuk mengirimkan e-mail, sehingga data yang diinginkan harus menunggu karyawan tersebut kembali ke kantor.

Dibutuhkanlah mekanisme penyimpanan data yang terorganisir dengan baik dan murah, dimana seluruh data terintegrasi dalam satu file server yang memliki kapasistas penimpanan data yang besar, sehingga karyawan tidak perlu direpotkan dengan menyimpan data di flashdisk serta tidak butuh waktu yang lama untuk mencari data yang diinginkan, salah satunya menggunakan sistem NAS dengan menggunakan Raspberry $\mathrm{Pi}$ sebagai server-nya sehingga dapat lebih murah dibanding PC. Tujuan dari penelitian ini adalah membangun sistem penyimpanan data dengan Network Attached Storage (NAS) berbasis Raspberry Pi di LP3SDM AZRA Palembang.

\section{METODE PENELITIAN}

\subsection{Jenis Penelitian}

Metode penelitian yang digunakan dalam penelitian ini ialah metode Research and Development (R\&D), yaitu metode penelitian dengan menerapkan langkah-langkah yang ada untuk menghasilkan sebuah produk yaitu media penyimpanan data menggunakan NAS berbasis Raspberry Pi. Langkah-langkah metode R\&D yaitu: (1) penelitian dan pengumpulan data; (2) perencanaan; (3) pengembangan draft produk; (4) uji coba lapangan awal; (5) merevisi hasil uji coba; (6) uji coba lapangan; (7) penyempurnaan produk hasil uji coba lapangan; (8) uji pelaksanaan lapangan; (9) penyempurnaan produk akhir; (10) diseminasi dan implementasi (Pelupessy \& Agustin, 2014).

\subsection{Metode Pengumpulan Data}

Teknik pengumpulan data pada penelitian ini melalui observasi, wawancara dan dokumentasi. Observasi dilakukan dengan cara mengamati bagaimana proses penyimpanan dan pertukaran data yang dilakukan karyawan di LP3SDM AZRA Palembang. Wawancara dilakukan dengan mencari informasi secara mendetil dari sumber wawancara. Wawancara dilakukan dengan ketua dan karyawan LP3SDM AZRA. Dokumentasi dengan cara mengumpulkan dokumen yang dapat berupa tulisan, gambar, dari lokasi penelitian

\subsection{Jenis Data}

Penelitian ini menggunakan dua sumber data, pertama data primer berupa catatan hasil pengamatan. terhadap cara kerja penyimpanan dan pertukaran data di LP3SDM AZRA Palembang serta hasil wawancara yang diperoleh melalui wawancara dengan ketua lembaga dan staf administrasi yang terlibat. Sumber data kedua adalah data sekunder yang didapatkan dari literatur dan jurnal yang berhubungan dalam penelitian ini. Data yang didapatkan selanjutnya akan analisis secara kualitatif untuk mendapatkan permasalahan yang akan dipecahkan.

\subsection{Metode Perancangan Jaringan}

Metode perancangan jaringan yang digunakan dalam penelitian ini adalah metode NDLC (Network Development Life Cycle). Tahapan NDLC seperti pada Gambar 1, dalam penelitian ini mencakup beberapa tahapan yaitu: a) Analisis, yaitu menganalisis kebutuhan dalam melaksanakan penelitian antara lain analisis kebutuhan sistem; b) Design, pada tahapan ini akan dibuat desain jaringan antara lain desain topologi jaringan NAS; c) Simulasi prototype, yaitu membangun rancangan jaringan NAS berbasis Raspberry $\mathrm{Pi}$; d Implementasi, yaitu konfigurasi Raspberry Pi dan konfigurasi NAS; e) Monitoring, yaitu kegiatan mengamati jaringan NAS agar dapat berjalan dengan baik. Tahapan perancangan dalam penelitian ini hanya sampai tahapan monitoring saja.

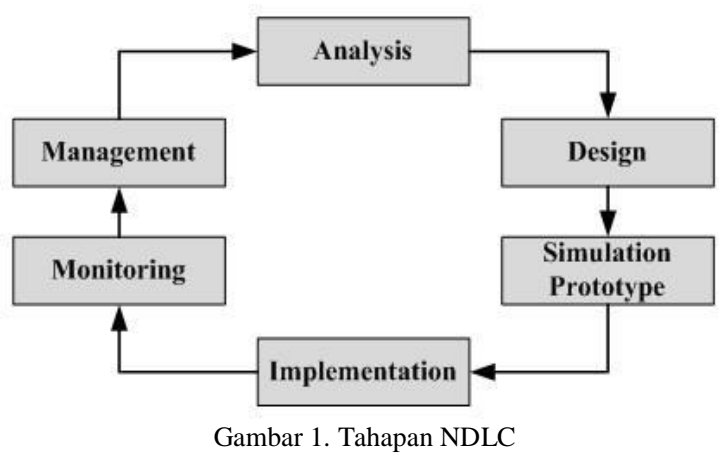

\section{HASIL DAN PEMBAHASAN}

Hasil dari penelitian ini berupa Network Attached Storage (NAS) berbasis Raspberry Pi yang dapat melayani proses penyimpanan dan pertukaran data di LP3SDM AZRA Palembang .

\subsection{Analisis Kebutuhan}

Tahapan awal dalam membangun NAS berbasis Raspberry Pi adalah analisis. Analisis yang dilakukan pada tahap ini antara lain analisis 
kebutuhan sistem baik perangkat keras pada Tabel 1, maupun perangkat lunak pada Tabel 2.

\begin{tabular}{|c|c|c|}
\hline Hardware & & Spesifikasi \\
\hline Raspberry & SoC & Broadcom BCM2837 \\
\hline Pi 3 & $\mathrm{CPU}$ & 4x ARM Cortex-A53, \\
\hline \multirow[t]{7}{*}{ Model B } & GPU & $1.2 \mathrm{GHz}$ \\
\hline & RAM & Broadcom VideoCore IV \\
\hline & Storage & 1GB LPDDR2 (900 MHz) \\
\hline & & 8 GB Micro SD \\
\hline & Networking & $\begin{array}{l}\text { 10/100 Ethernet, } 2.4 \mathrm{GHz} \\
802.11 \text { wireless, Bluetooth } 4.1\end{array}$ \\
\hline & Port & Classic \\
\hline & & $\begin{array}{l}\text { HDMI, } 3.5 \mathrm{~mm} \text { analogue audio- } \\
\text { video jack, } 4 \mathrm{x} \text { USB } 2.0 \text {, } \\
\text { Ethernet, Camera Serial } \\
\text { Interface (CSI), Display Serial } \\
\text { Interface (DSI) }\end{array}$ \\
\hline Laptop & CPU & Intel Core i5-7200U \\
\hline \multirow[t]{4}{*}{ Config } & RAM & 4GB DDR4 \\
\hline & Storage & HDD 500GB \\
\hline & Networking & $\begin{array}{l}10 / 100 \text { Ethernet, } 2.4 \& 5 \mathrm{GHz} \\
802.11 \text { bgn wireless, Bluetooth } \\
4.0\end{array}$ \\
\hline & Port & HDMI , USB2.0, USB3.0 \\
\hline Laptop & CPU & Intel Atom atau lebih \\
\hline \multirow[t]{4}{*}{ Client } & RAM & $1 \mathrm{~GB}$ atau lebih \\
\hline & Storage & 160GB atau lebih \\
\hline & Networking & $\begin{array}{l}\text { 10/100 Ethernet, } 2.4 \mathrm{GHz} \\
\text { 802.11bgn wireless }\end{array}$ \\
\hline & Port & USB 2.0 \\
\hline $\begin{array}{l}\text { Hardisk } \\
\text { Eksternal }\end{array}$ & Storage & HDD 1TB \\
\hline
\end{tabular}

\begin{tabular}{lll}
\multicolumn{2}{c}{ Tabel $2 . S p e s i f i k a s i$} & Perangkat Lunak \\
\hline \multicolumn{1}{c}{ Software } & & Spesifikasi \\
\hline Raspberry Pi 3 & OS & Raspbian \\
Tipe B & Program & Samba \\
Laptop Config & OS & Windows 10 \\
& Program & Putty \\
Client & OS & Windows 7 atau lebih \\
\hline
\end{tabular}

\subsection{Perancangan}

Tahapan selanjutnya adalah desain topologi jaringan seperti pada Gambar 2.

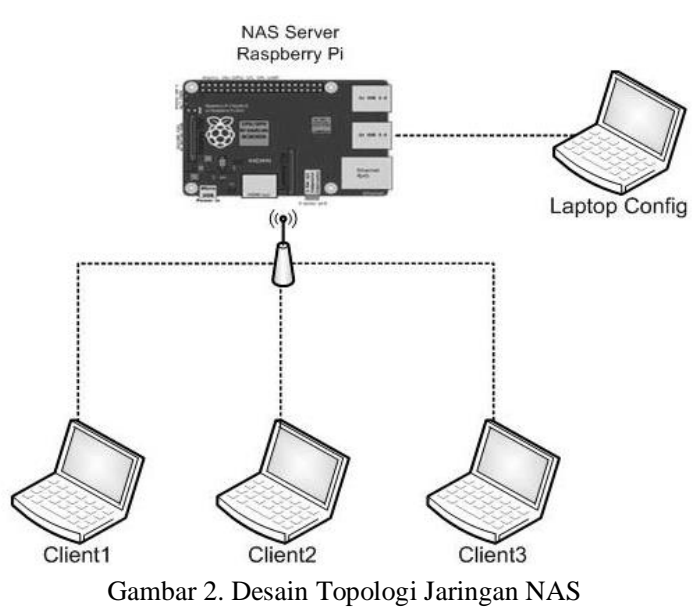

Topologi jaringan pada Gambar 2 menggunakan konsep jaringan client-server. Raspberry Pi digunakan sebagai NAS server dan access point menggunakan USB Wifi adapter, sedangan untuk konfigurasi NAS server menggunakan laptop sebagai administrator yang dihubungkan dengan cara me-remote Raspberry Pi. Untuk client menggunakan 3 buah laptop yang terkoneksi ke NAS server melalui access point wifi.

\subsection{Simulasi Prototype}

Tahapan ini meliputi membuat prototype NAS menggnunakan Raspberry Pi 3 yang dihubungkan dengan Hardisk eksternal, kemudian dihubungkan ke laptop untuk selanjutnya ke tahapan implementasi dan konfigurasi, seperti pada Gambar 3.

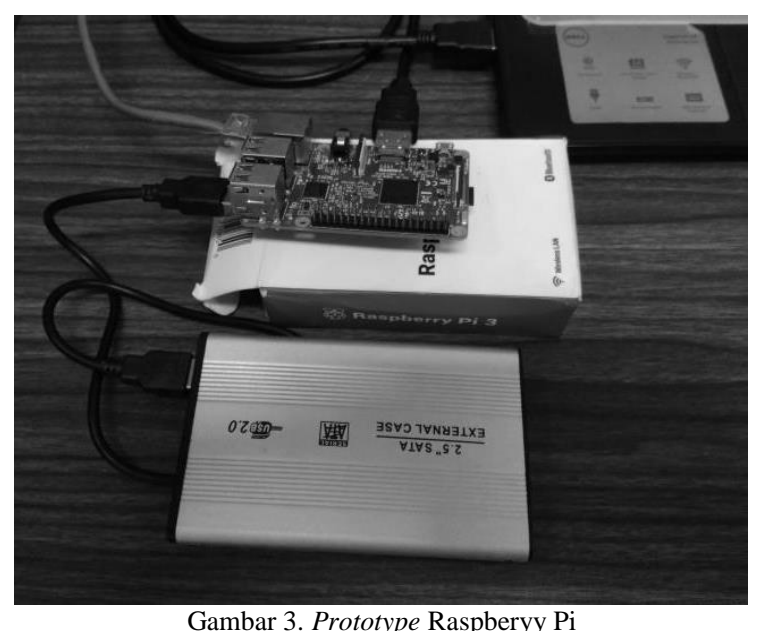

\subsection{Implementasi}

Tahapan selanjutnya adalah instalasi dan konfigurasi Raspeberry Pi sebagai NAS server. Langkah pertama adalah menginstal sistem operasi di perangkat Raspberry Pi 3 menggunakan sistem operasi Raspbian. Sistem operasi tersebut akan diinstall pada SD Card yang telah dipasang, menggunakan beberapa aplikasi pendukung seperti WinDiskImager. Proses instalasi OS Raspbian dapat dilihat pada Gambar 4.

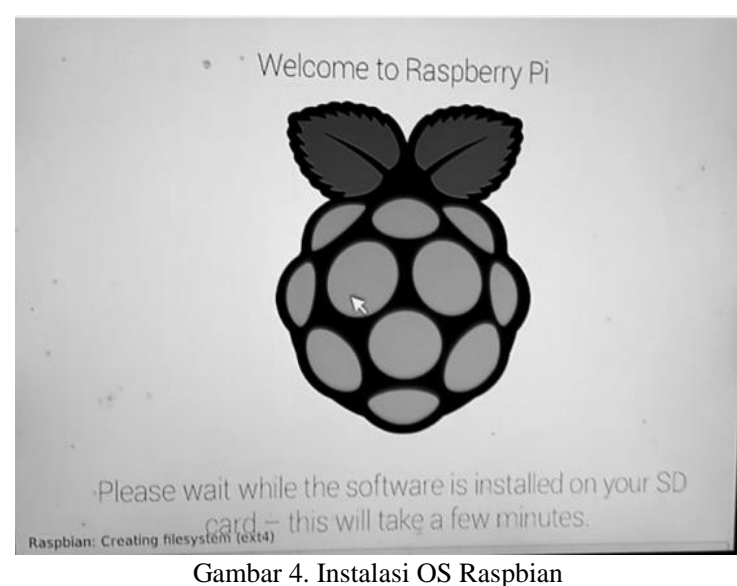

Untuk dapat menggunakan sistem operasi yang dapat diakses melalui jaringan, aktifkan protokol Secure Shell (SSH) yang dapat diakses 
menggunakan kabel UTP. Setelah selesai proses reboot, kemudian pemberian IP address pada perangkat Raspberry agar dapat diakses oleh client melalui jaringan.

Selanjutnya adalah pemberian IP address static pada laptop konfigurasi agar dapat terkoneksi dengan perangkat Raspberry Pi 3. IP address Raspberry yang digunakan adalah 192.168.1.0, kemudian pengaturan LAN Ethernet pada perangkat laptop konfigurasi menggunakan IP address 192.168.1.1 dengan subnet mask 255.255.255.0, seperti pada Gambar 5.

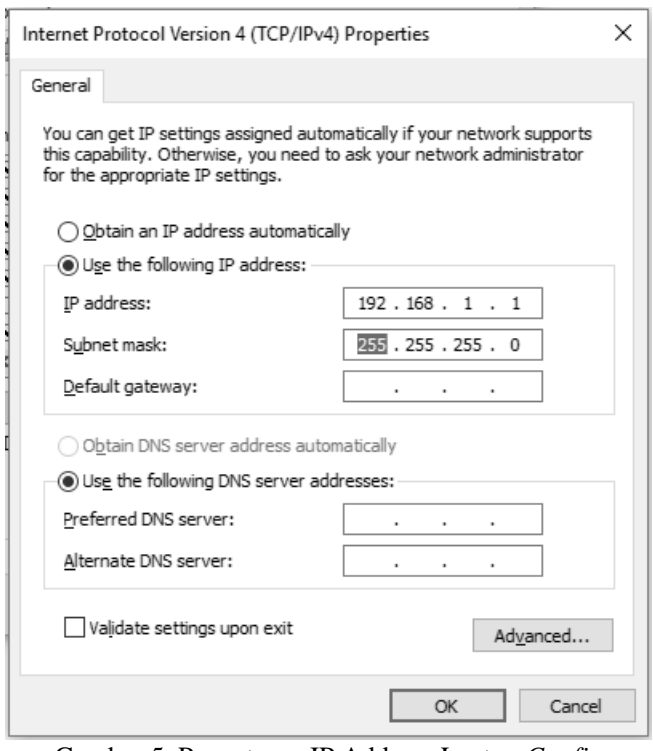

Gambar 5. Pengaturan IP Address Laptop Config

Agar Raspberry Pi dapat diakses dari windows melalui jaringan, gunakan aplikasi PuTTY. Langkah berikutnya adalah meng-update sistem operasi Raspbian. Selanjutnya instalasi dan konfigurasi access point agar client dapat terhubung dengan Raspberry $\mathrm{Pi}$ melalui jaringan wifi, dibutuhkan beberapa aplikasi tambahan seperti hostapd dan isc-dhcp-server yang diinstal di Raspberry $\mathrm{Pi}$, kemudian instalasi driver access point untuk wireless USB adapter, dilanjutkan dengan konfigurasi IP address static untuk wireless yang ada di Raspberry Pi, seperti pada Gambar 6.

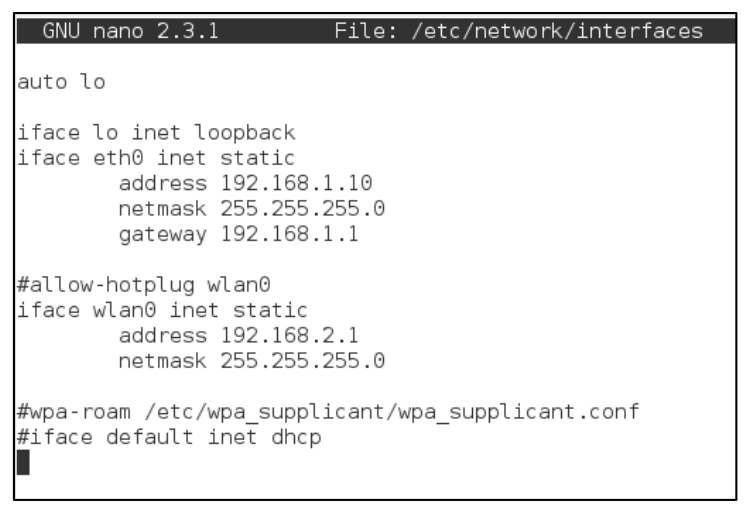

Gambar 6. Konfigurasi IP address wireless
Setelah semua proses selesai selanjutnya reboot OS Raspbian agar dapat menerapkan semua hasil konfigurasi. Agar hardisk eksternal yang terpasang pada Raspberry Pi dapat diakses melaui jaringan yang berbeda sistem operasi antara Raspbian dan windows, dibutukan paket aplikasi Samba. Lakukan instalasi paket software ntfs-3g dan paket samba serta samba-common-bin. Kemudian buat direktori pada USB harddisk dan lakukan mount otomatis pada USB harddisk ketika sistem dijalankan, kemudian buat pengaturan hak akses dan authentikasi dari direktori USB harddisk yang akan di sharing, seperti pada Gambar 7.

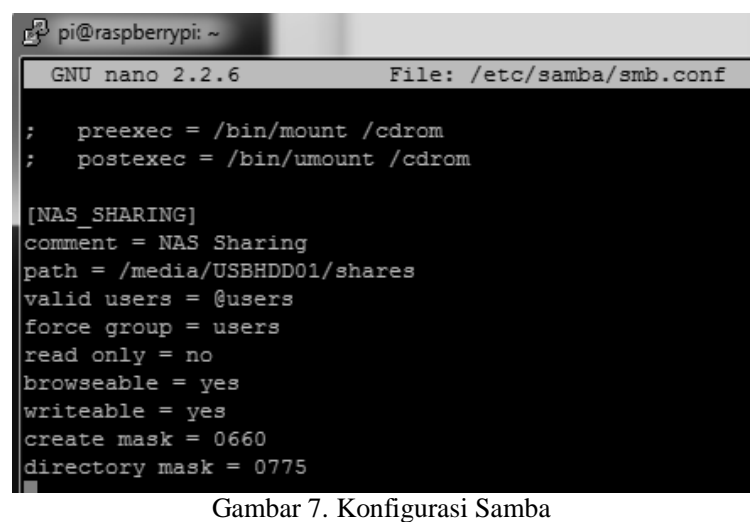

Langkah terakhir adalah membuat user untuk 3 client melalui terminal menggunakan perintah "useradd", kemudian tambakan ke dalam user samba.

\subsection{Monitoring}

Tahapan monitoring yang dilakukan dalam penelitian ini adalah pengujian sistem agar dapat berjalan dengan baik. Hasil pengujian sistem NAS dapat dilihat pada Gambar 8.

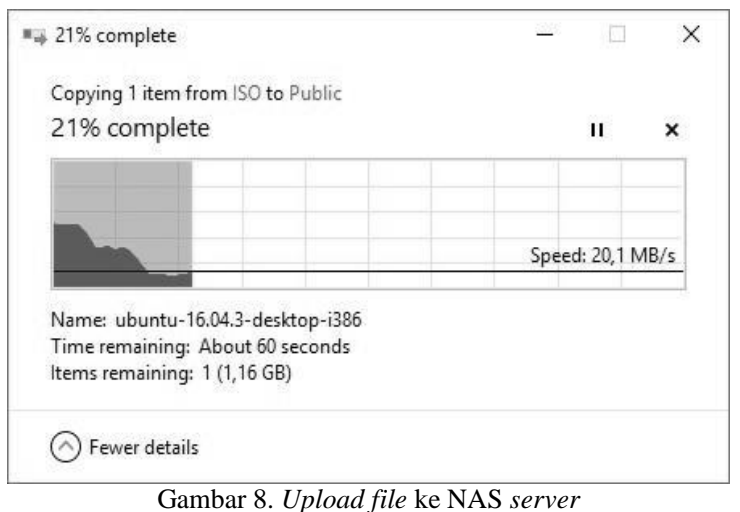

Hasil pengujian lengkap server NAS dapat dilihat pada Tabel 3. Berdasarkan Tabel 3 dapat dilihat bahwa untuk mengakses ke direktori NAS laptop config dan client dapat dilakukan dengan lancar tanpa ada hambatan dan tanpa ada jeda waktu, begitu juga dalam meng-upload dan men-download file dari dan ke server NAS lancar tanpa hambatan. 


\begin{tabular}{cll}
\multicolumn{3}{c}{ Tabel 3. Hasil Pengujian NAS } \\
\hline Perangkat & \multicolumn{1}{c}{ Pengujian } & \multicolumn{1}{c}{ Hasil } \\
\hline Laptop Config & Akses ke direktori & Lancar \\
& Upload file & Lancar \\
& Download file & Lancar \\
Client 1 & Akses ke direktori & Lancar \\
& Upload file & Lancar \\
& Download file & Lancar \\
Client 2 & Akses ke direktori & Lancar \\
& Upload file & Lancar \\
& Download file & Lancar \\
Client 3 & Akses ke direktori & Lancar \\
& Upload file & Lancar \\
& Download file & Lancar \\
\hline
\end{tabular}

\section{KESIMPULAN}

Penelitian ini menghasilkan produk file server menggunakan eksternal harddisk untuk menempatkan semua dokumen. Setiap karyawan diberi hak akses berupa username dan password untuk mengakses perangkat dan mengakses dokumen yang sama. Penerapan NAS berbasis Raspberry Pi di LP3SDM AZRA Palembang dapat memudahkan pekerjaan serta berbagi data lebih cepat. NAS berbasis Raspberry Pi yang dibangun merupakan sistem penyimpanan data yang murah, karena tidak memerlukan spesifikasi komputer yang tinggi serta tidak membutuhkan lisensi perangkat lunak.

Untuk pengembangan selanjutnya perlu ditingkatkan bukan hanya pc atau laptop tetapi juga bisa diakses melalui smartphone. Dapat menambahkan HDD docking station agar dapat memberikan daya yang lebih baik ke hardisk eksternal.

\section{DAFTAR PUSTAKA}

DEFNI \& PRABOWO. 2013. Perancangan dan Implementasi Data Loss Prevention System dengan menggunakan Network Attached Storage. Jurnal TEKNOIF, Institut Teknologi Padang, Vol.1 (2), p.45-60. [ejournal]. Tersedia melalui: <https://ejournal.itp.ac.id/index.php/tinform atika/article/view/145/144> [Diakses 10 Juli 2018]

DHARMENDRA, I KOMANG \& DESIANI, LUH PUTU AYU. 2015. Penerapan Network Attached Storage Menggunakan Openwrt Studi Kasus: Bagian Kemahasiswaan STIKOM Bali. Proceeding KNS\&I. p.1016-1020. STMIK STIKOM Bali, [ejournal]. Tersedia di: <http://ejournal.stikom-bali.ac.id/index.php /knsi/article/view/551> [Diakses 13 Juli 2018]

HALIM, R.M NASRUL. 2016. Rancang Bangun Sistem Pengolahan Data Peserta Diklat di LP3SDM AZRA Palembang. Jurnal Ilmiah Matrik, Universitas Bina Darma, Vol.18(3), p.261-270. [e-journal]. Tersedia di:
$<$ http://jurnal.binadarma.ac.id/index.php/jur nalmatrik/article/view/508/267> [Diakses 10 Juli 2018]

JANNAH, MIFTAHUL, dkk. 2015. Rancang bangun network attached storage (NAS) pada raspberry pi untuk penyimpanan data terpusat berbasis WLAN. Jurnal Ilmiah FIFO, Universitas Mercu Buana, Vol.7(2), p.222-234. [e-journal]. Tersedia melalui: <http://publikasi.mercubuana.ac.id/index.p hp/fifo/article/view/1257> [Diakses 10 Juli 2018]

PELUPESSY, ELFIRA TAUFIDA \& AGUSTIN, RR. HAPSARI PENI. 2014. Pengembangan Media Pembelajaran Berbasis E-Learning Pada Mata Kuliah Fisika 1 Untuk Meningkatkan Efektifitas Belajar Mahasiswa. Jurnal Pendidikan Teknik Elektro, Universitas Negeri Surabaya, Vol. 3(2), p.193-198. [e-journal]. Tersedia melalui: <https://jurnalmahasiswa. unesa.ac.id/index.php/jurnal-pendidikanteknik-elektro/article/viewFile/8442/3908> [Diakses tanggal 11 Oktober 2018]

YUWONO, BAMBANG, dkk. 2015. Pengembangan Model Public Monitoring System menggunakan Raspberry Pi. Jurnal Telematika UPN Veteran,, Vol.12(2), p.122-123. [e-journal]. Tersedia melalui <http://jurnal.upnyk.ac.id/index.php/telema tika/article/view/1409> [Diakses 13 Juli 2018] 